\title{
ENSAYO
}

\section{Perspectivas integradoras en Antropología Forense. Análisis de caso}

\author{
Integrative perspectives in Forensic Anthropology. Case analysis
}

\author{
José H. Miceli ${ }^{1}$ \\ Susana S. Salceda ${ }^{2}$ \\ Silvia Ríos ${ }^{3}$ \\ Guillermo Lamenza ${ }^{4}$ \\ Horacio A. Calandra ${ }^{5}$
}

Tipo de artículo: Ensayo. Recibido: 30 de octubre de 2019. Aprobado: 09 de diciembre de 2019

Resumen: El presente trabajo tiene el propósito de ejemplificar, a través del análisis de un caso, la concurrencia de disciplinas antropológicas, y otras afines, en la interpretación de un hecho delictivo. La participación de especialistas vinculados para interpretar signos específicos relacionados con el culto y la "religiosidad popular" alertó, a través de la producción de información fehaciente, al sistema de justicia, y permitió encausar la investigación del hecho delictivo en el marco de una intrincada trama de interrelaciones entre personas con roles sociales diferenciados. En este caso el hecho está íntimamente relacionado con los actores sociales de una localidad del interior de la provincia de Corrientes (Mercedes, Argentina). En Argentina este quehacer, con reconocimiento institucional, abarca actividades que involucran casos forenses aislados como el que en esta oportunidad se presenta, así como importantes crímenes de lesa humanidad vinculados a genocidios en masa en contextos de violencia social, espacio fundamentalmente ocupado por organizaciones no gubernamentales encargadas de la defensa de los derechos humanos.

Palabras clave: bioarqueología, antropología forense, antropología pública, etnografía forense.

Abstract: The present work has the purpose of exemplifying, through the analysis of a case, the concurrence of anthropological disciplines, and other related ones, in the interpretation of a criminal act. The participation of specialists linked to interpreting specific signs related to the cult and "popular religiosity" alerted, through the production of reliable information, the justice system, and allowed to prosecute the investigation of the criminal activity within the framework of an

\footnotetext{
1 Gabinete de Investigaciones Antropológicas (Corrientes, Argentina).

2 Facultad de Ciencias Naturales y Museo, Universidad Nacional de La Plata (Argentina). Consejo Nacional de Investigaciones Científicas y Tecnológicas (CONICET), Argentina.

3 Gabinete de Investigaciones Antropológicas (Corrientes, Argentina).

4 Facultad de Ciencias Naturales y Museo, Universidad Nacional de La Plata (Argentina). Consejo Nacional de Investigaciones Científicas y Tecnológicas (CONICET), Argentina.

5 Consejo Nacional de Investigaciones Científicas y Tecnológicas (CONICET), Argentina.
} 
intricate plot of interrelationships between people with differentiated social roles. In this case, the fact is closely related to the social actors of a town in the interior of the province of Corrientes (Mercedes, Argentina). In Argentina, this task, with institutional recognition, includes activities that involve isolated forensic cases such as the one presented at this time, as well as important crimes against humanity linked to mass genocides in contexts of social violence, space mainly occupied by non-governmental organizations responsible for the defense of human rights.

Keywords: bioarchaeology, forensic anthropology, public anthropology, forensic ethnography.

Cómo citar este artículo: Miceli, J. H., Salceda, S. S., Ríos, S., Lamenza, G. y Calandra, H. A. (2020). Perspectivas integradoras en Antropología Forense. Análisis de caso. Memorias Forenses, (3), 85-98.

\section{Introducción}

El nacimiento y desarrollo histórico del quehacer antropológico forense en América, ocurrido en la segunda mitad del siglo XX, se constituyó en una especialidad de la antropología física centrada en la identificación de restos óseos humanos y causales de decesos (Stewart, 1979; Krogman e İşcan, 1986).

En particular, en Sudamérica, este desarrollo quedó ligado casi exclusivamente a contextos de violencia laboral y política. Argentina, Bolivia, Brasil, Chile, Paraguay y Uruguay, entre otros países de América latina, convulsionados por largos períodos de violencia extrema, se vieron sujetos a violaciones sistemáticas y agresivas de los derechos humanos a partir del acceso al poder de gobiernos militares civilmente apoyados. A principios de los años ochenta del siglo XX, progresiva y secuencialmente, estos países comenzaron a transitar el nostalgioso acceso a la democracia, proceso que trajo aparejado desempolvar sus cartas magnas y aprender a dialogar y a respetar derechos normados. De este modo, la constitución de foros múltiples, la revisión de normas, la creación de organizaciones para consolidar el frágil retoño, todo ello sin dejar de investigar y juzgar a quienes fueran responsables de claros delitos de lesa humanidad, se tornaron imprescindibles. En particular en Argentina, a partir de diciembre de 1983, el retorno a la democracia tuvo como correlato la creación de la Comisión Nacional sobre Desaparición de Personas (Conadep), organización que requirió la ayuda internacional de la Asociación Americana para el Avance de la Ciencia (EE. UU.), la cual envió una delegación de científicos forenses y genetistas, entre ellos Clyde Snow, uno de los más reconocidos expertos en antropología forense a nivel internacional (Politis, 2002). Con este padrinazgo y en este contexto histórico, surgió el Equipo Argentino de Antropología Forense con ejercicio pleno de sus actividades públicamente reconocidas en el campo de los grandes genocidios.

Este hecho motivó la validación a nivel internacional de un "nuevo campo" de aplicación de la antropología, con énfasis en bioantropología y arqueología, dándole a la disciplina un papel preponderante en foros legales y públicos, reconociendo también a las ciencias antropológicas como formadoras de memoria (Zarankin y Fondebrider, 2007). Aun así, este sesgo limitó avances más prolíficos en las posibilidades aplicativas disciplinares, al tiempo que produjo un relativo distanciamiento del episteme antropológico y de su enfoque distintivo sobre la interrelación biología-cultura integrada a los distintos medio ambientes con una visión sistémica.

De todos modos, y aunque el quehacer de la antropología forense como campo de aplicación estuvo asociado al esclarecimiento de acciones de terrorismo de Estado, nunca se contrapuso temáticamente con otra tarea abordada desde fines de la década de los setenta que comprendió y comprende los estudios periciales por demanda de instituciones de seguridad y justicia con competencia en el ámbito judicial (Chaves de Azcona, 1971; Salceda, Calandra y Villanueva, 2010). 
En una apretada síntesis puede reseñarse la delimitación histórica de este campo de aplicación. Es un hecho que en América los antropólogos físicos colaboraron durante muchos años con los médicos legistas y con las instituciones de ejecución de la ley, pero lo hicieron sin ningún estándar de calificación oficialmente reconocido. En 1972, la creación de la Sección Antropología en la Academia Americana de Ciencias Forenses (USA) marcó el comienzo de una nueva etapa y desde allí se puede narrar el desarrollo histórico de la antropología forense como disciplina con dominio propio, que la condujo a lograr su estatus actual (Cattaneo, 2006; Fondebrider, 2007; Miceli y Ríos, 2009).

¿Cómo llega la antropología a ser parte de ese campo auxiliar multidisciplinario del sistema médicolegal? Valga la pionera experiencia norteamericana para ilustrar el proceso. La Academia Americana de Ciencias Forenses se constituyó en 1950 a partir del esfuerzo de R. H. Gradwolh con el objetivo de "alentar la educación e investigación en las ciencias forenses para estimular el estudio, perfeccionar la práctica, elevar el estándar y avanzar la causa de las ciencias forenses; promover la comunicación interdisciplinaria ...". Antes de 1970, solamente dos antropólogos físicos, W. Krogman y E. Kerley, se habían integrado a la academia como parte de la sección general. En particular, fue Kerley quien propuso la creación de una sección de antropología física reuniendo el apoyo de antropólogos estadounidenses. Así, en 1972, se institucionalizó la antropología física como disciplina en el seno de la Academia Americana de Ciencias Forenses. Poco tiempo después, en 1973, se creó la Fundación de Ciencias Forenses, con el objetivo de establecer idoneidad profesional a través de diversas juntas de evaluacióny certificación. Con todo este bagaje puede reseñarse cronológicamente el año 1978 como el del establecimiento formal de la antropología forense, novel campo donde se aplicaron las investigaciones y se validaron los procedimientos y metodologías de la bioantropología en temáticas variadas como crecimiento, nutrición, paleodemografía y osteología que, sustentados en estudios realizados en poblaciones, se pusieron a prueba en la diagnosis de rasgos con valor identificativo. Tanto es así que trabajos de ese período relacionados con la estimación de edad a partir de la secuencia en la erupción dentaria y/o en la osificación esquelética siguen vigentes.

También hoy, en nuestro país, aportes sustantivos en la dilucidación de casos dirimidos en foros públicos provienen del conjunto de las disciplinas antropológicas, con demanda creciente, en función de las problemáticas de las que se trate. Es así que la arqueología y la etnografía se integran plenamente sistematizando sus investigaciones para estos fines, y definiendo, conjuntamente con la biología, un nuevo campo al que denominamos antropología pública. A esto se suma el reconocimiento de los derechos de pueblos preexistentes u "originarios" reconocidos constitucionalmente en la legislación nacional e internacional, en el Artículo 75 de la Constitución de la Nación Argentina de 1994.

Todo ello requirió de un espacio de investigaciónacción donde el sector científico responde a los requerimientos de la comunidad bajo la norma no escrita de que los conceptos expuestos conforman una relación justa y equilibrada entre ambos sectores y, en particular, en una situación de litigio, sea por posesión de tierras, sea ante denuncias penalizables y otras razones en las que se entrelazan aspectos científicos, legales y éticos (Gassiot y Palomar, 2000; Desántolo et al., 2013; Salceda, Desántolo y Plischuk, 2015).

Asimismo, la academia capitalizó esta relación a través de investigaciones que integran cuerpos eruditos (Martínez, 2000; Plischuk, 2012; Desántolo, 2013; García, 2013), de la implementación de carreras universitarias para la formación de recursos humanos de posgrado (Facultad de Derecho, Universidad Nacional de La Plata, Argentina), de la creación de centros de investigación en ámbito universitario (CICIF, Facultad de Ciencias Médicas, Universidad Nacional de La Plata, Argentina) y de la participación activa en foros civiles y penales de investigadores forjados en el sistema científico formal para la resolución concreta de casos (Dasso, Palmer, Braunstein y Pignocchi, 2006; Salceda, Calandra y Restelli, 2007; Salceda et al., 2009).

En el presente artículo, considerando la antropología forense como una aplicación de la ciencia antropológica con todas sus especialidades 
concurrentes, se aborda un caso criminal testigo que renueva la visión antropológica de la investigación a partir de su tratamiento y resultados.

\section{El caso "Ramoncito"}

En el año 2006, en la localidad de Mercedes (-2911',5895') en la provincia de Corrientes, nordeste de Argentina, se halló el cadáver de un niño de 12 años en un paso a nivel urbano. Estaba decapitado, ni su cuerpo ni el contexto contenían sangre, presentaba signos evidentes de haber sido ultrajado y el cráneo, totalmente escalpado, no tenía restos de piel ni de otros tejidos blandos.

Tanto el Acta de Circunstancia Compuesta como el Protocolo de Autopsia (N. 3124) realizado en el Cuerpo Médico Forense del Poder Judicial de la Provincia de Corrientes (Argentina), resumen supuesta identificación, decapitación, laceraciones en el lado izquierdo del cuerpo, y atribuyen el estado del cráneo a la posible acción de perros que merodeaban el lugar.

Tras cuarenta días de investigación policial sin resultados concretos, las autoridades judiciales requirieron la colaboración del Gabinete de Investigaciones Antropológicas de la Provincia de Corrientes (Argentina) a través de su director, Lic. José Miceli, por sospechas aisladas de motivaciones mágico-religiosas en el crimen. De este modo se dio inicio a una exhaustiva investigación etnográfica que, utilizando métodos y técnicas propias de la disciplina, comenzó por analizar las numerosas imágenes fotográficas del cuerpo, haciendo hincapié, particularmente, en la semiótica de las lesiones que presentaba. Estas lesiones incluían el prolijo escalpado, las infligidas en el lado izquierdo del cuerpo, marcas, quemaduras y aquellas que aparentaban ser un intento fallido de amputación de una pierna. También las imágenes de la autopsia mostraban ausencia de algunas vértebras cervicales imposibles de individualizar.
Asimismo, la investigación etnográfica incluyó el análisis del lugar del hallazgo, es decir, el escenario inmediato y mediato del espacio donde fuera depositado el cuerpo y su posición en ese contexto. Cabe señalar que en las proximidades del cuerpo, además, se identificaron vegetales silvestres que poseen significados místicos y mágicos como el tártago (Ricinus communis $L$., de la familia de las euforbiáceas) hacia la izquierda del cuerpo y las tacuaras (Guadua angustifolia) frente al mismo (Miceli, 1998).

\section{Encausando la causa}

El avance logrado por los aportes del "análisis etnográfico del crimen" y la insatisfacción producida por las dudas inducidas por el informe de autopsia, llevaron a las autoridades judiciales a convocar a expertos en bioantropología y arqueología forense, quienes sumaron al equipo un médico histólogo, para contrastar las hipótesis formuladas que sostenían un crimen de motivación mágico-religiosa y ejecución ritual.

El 27 de marzo del 2007, el Juez Subrogante SS Dr. Gustavo René Buffil libra autorización para el inicio de acciones periciales por parte del Equipo Forense del Museo de La Plata, puntualizando requisitorias específicas desde el interés judicial a saber (Figura 1):

Establecer conclusiones sobre: 1. Hora de muerte de la víctima; 2. Grupo sanguíneo; 3. Dirección de los cortes; 4. La posición del victimario al producir la lesión mortal; 5. Las características particulares del arma utilizada en las distintas acciones sufridas por la víctima; 6. Diferenciación de acciones antrópicas y no-antrópicas sobre los restos; 7. Determinación de la secuencia temporal de otras lesiones; 8. Del modo en que se produjo la ausencia de lengua y piso de boca; 9. La correspondencia individual entre cráneo y cuerpo hallados; 10 . Todo aquel dato que los especialistas consideren de interés para la causa, y notificando fehacientemente a los miembros del Cuerpo Forense del Museo de La Plata. 


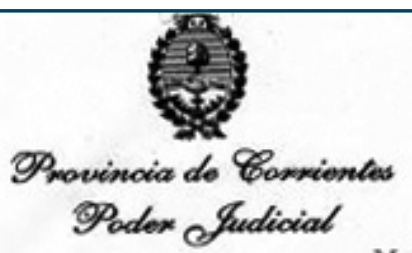

Mercedes 27 de marzo de! 2007.

I Vistos: el estado de autos, la autorizacion del Superior Tribunal de Josticia respecto a los fcedoe $y$ a la organización del traslado de los pertios, segus fs. 854, en encontrandose el gropo de especialistas del museo antropologia de la Facultad de ciencias Naturales y Museo de ta Tniversidad de la Plata en ectoe Tribunales;

Resaelva: 19 Ordenar al equipo Medico del Museo de la cindad de La Plata Provincia de Bs. As., Integrado por et Dr. Mario Restelli, Horacio Calandra y Susana Salseda para que procedan informar con carácter pericial de acorde sos especialidades, respecto a los etudios agregados en autos, y en base a ello concluyan sobre Hors de la Muerte de la Victima, el grupo sanguineo de la Victima la dirección de les ecrtes, si el Victimario estaba sentado, parads, of fa altura desde doede se realizo el corte, si el ama con el que se quito la vida a la victima, era un arma de filo óentado o tiso, con que elementos se ha retirado de la cabeze y el cuello los tejidos blando mencionados en el punto dos del protocolo de autopsia, si fue la mordedura de un animal, si fueron extraidos cuirurgicamente o manuahimente, o si fiteron extraidos en el mista o m omento de seccionarse el cuello - postericrmente, si las queenadaras en fa palmas izquierda de la mano de la victima son recientes o datan de ua tiempo mayor, el modo en que se prodajo la ausencia de la lenzua y del piso de la boca ; ai el cráneo hatlado correspoude af cuerpor, si la vioiación five posterior o anterior a le muerte y cualquier otro dato que loe especialistas estimen de interes para los presentex;

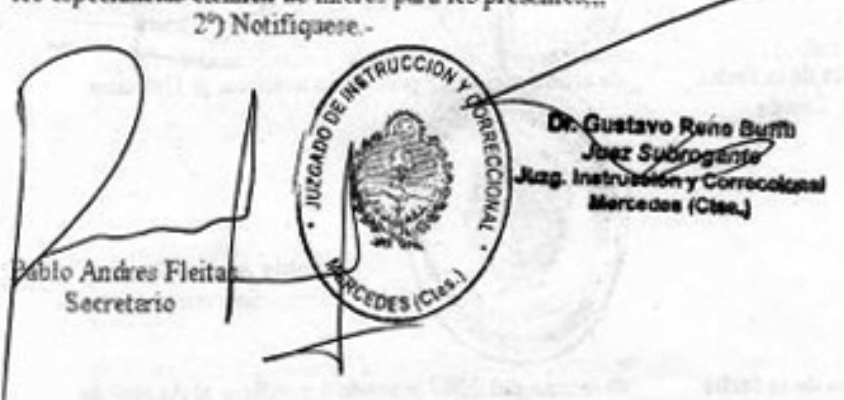

En el dia de la fecha 27 de earro del 2007 procedo notificar I Sr. Morio Restelli. Conste.

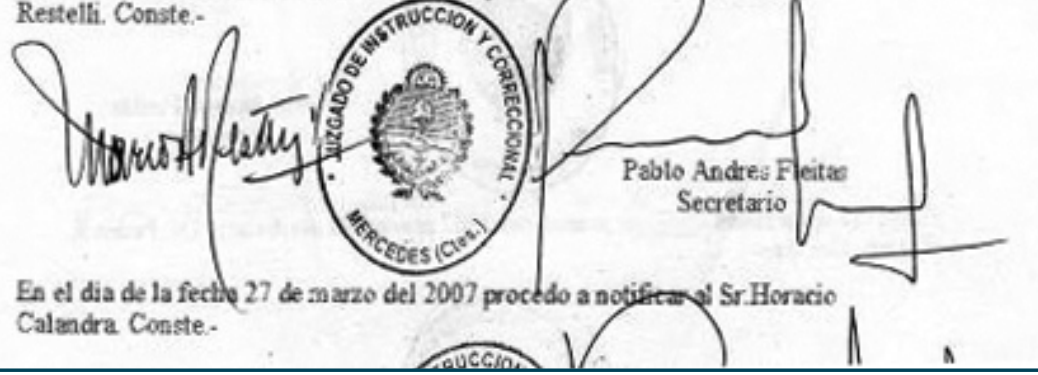

Figura 1. Oficio del juez subrogante al Equipo Forense del Museo de La Plata

Interiorizados del expediente judicial, prospectado el lugar del hallazgo y evaluados los informes periciales en concordancia con los requerimientos de la autoridad judicial competente, el equipo solicitó entrevistar a los profesionales médicos policiales y judiciales que intervinieron en la causa y, además, exhumar del cadáver. 
En la mañana del 29 de marzo de 2007, se procedió a la exhumación en el cementerio local en presencia de familiares de la víctima, autoridades judiciales, fiscal y abogados defensores, autoridades municipales, policía y bomberos voluntarios quienes presenciaron y/o colaboraron en la tarea supervisada por el Equipo Forense-La Plata (Figura 2). Utilizando técnicas específicas convenidas para tareas de campo arqueológicas, adecuadas al espacio inhumatorio, se procedió a la limpieza de la superficie de la tumba ( $1 \mathrm{~m} \times 2 \mathrm{~m})$, ubicada según el plano catastral del cementerio, en conocimiento de empleados jerárquicos del mismo, por una cruz de hierro y elementos alusivos a la funebridad. Se inició la excavación por niveles artificiales de $20 \mathrm{~cm}$ de espesor, con notoria dificultad fundamentalmente por la cantidad de agua incorporada al sedimento. Se cubrió la totalidad de la superficie en el primer nivel, operando del mismo modo en los niveles segundo y tercero $(0,20-0,40 \mathrm{~m}$ y 0,40 - 0,60 m). Los sedimentos removidos hasta allí evidenciaban alteraciones propias de los depósitos mixtos (naturales y artificiales), aspecto demostrado por la presencia de elementos no propios de los sedimentos naturales tales como trozos de ladrillo, vidrio, flores artificiales, trozos de tela, entre otros.

Al profundizar el espacio de inhumación y casi al finalizar el siguiente nivel $(0,80 \mathrm{~cm})$ comenzó a aparecer el borde del ataúd. Ya delimitado en su totalidad el espacio ocupado por el féretro, se consideró indispensable ampliar la superficie de excavación hacia los lados de manera que se facilitara su extracción. Se continuó descendiendo por los laterales, sin hurgar la zona de tapa dado su deficiente estado de preservación (Figura 3), y excavando la periferia con el objetivo de pasar por debajo del ataúd algún elemento rígido que permitiera su extracción de la manera más completa posible. El estado de conservación general era regular y el agua representaba el principal agente agresivo. Se logró despegar el féretro de su posición original realizando presiones desde distintos puntos, y fue sacado de la fosa colocándolo encima de una tabla de madera ubicada sobre un móvil de desplazamiento de ataúdes de uso común en el cementerio. En este momento se consideró necesario aliviar el peso retirando la tierra que aún quedaba depositada por encima de la tapa (Figura 4). Revisados exhaustivamente todos los sedimentos removidos durante la exhumación, se rotularon y embolsaron aquellos elementos necesarios para un eventual análisis posterior. Se trasladó el féretro en un vehículo policial hasta la morgue del hospital local Las Mercedes, lugar donde el equipo procedería e extraer los restos del ataúd para su análisis.

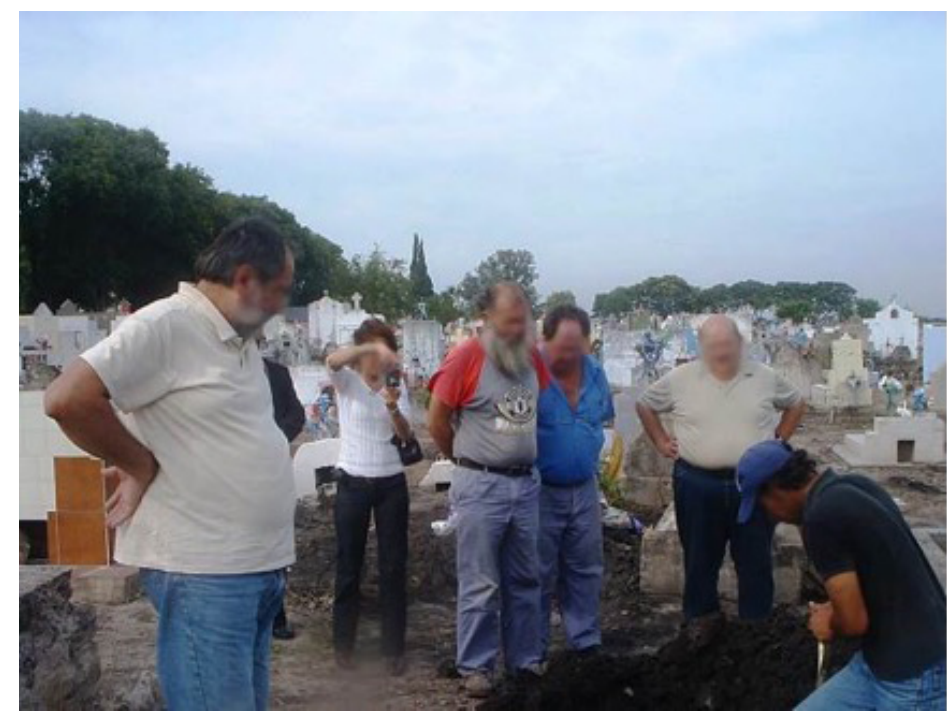

Figura 2. Tareas de excavación en el cementerio 


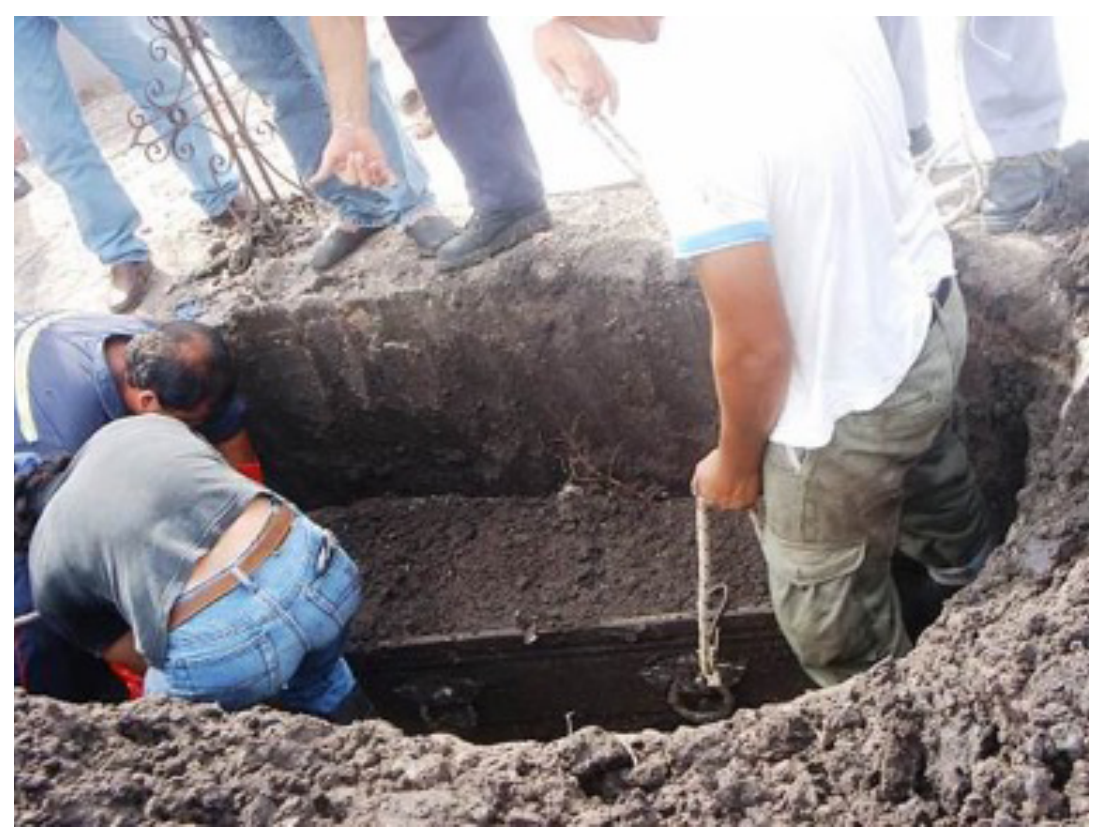

Figura 3. Exhumación del cuerpo

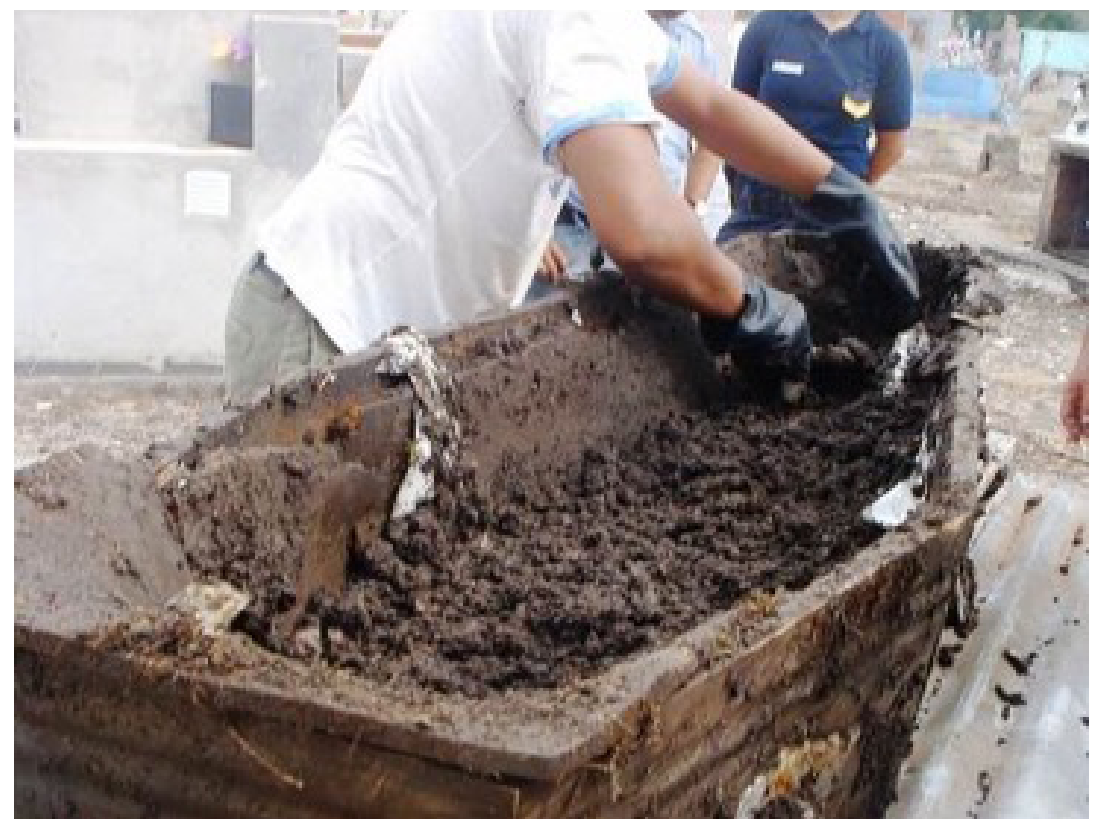

Figura 4. Retiro del excedente de tierra

El trabajo bioarqueológico consistió en registrar, localizar, identificar e inventariar las piezas disponibles verificando sus características generales y su disposición. La presencia de un cobertor de nailon colocado entre el piso del ataúd y el cuerpo facilitó la tarea, ya que al retener en el interior alrededor de $10 \mathrm{~cm}$ de agua mantuvo el esqueleto en estricta posición anatómica y aceleró la destrucción total de tejidos blandos (Figura 5). 


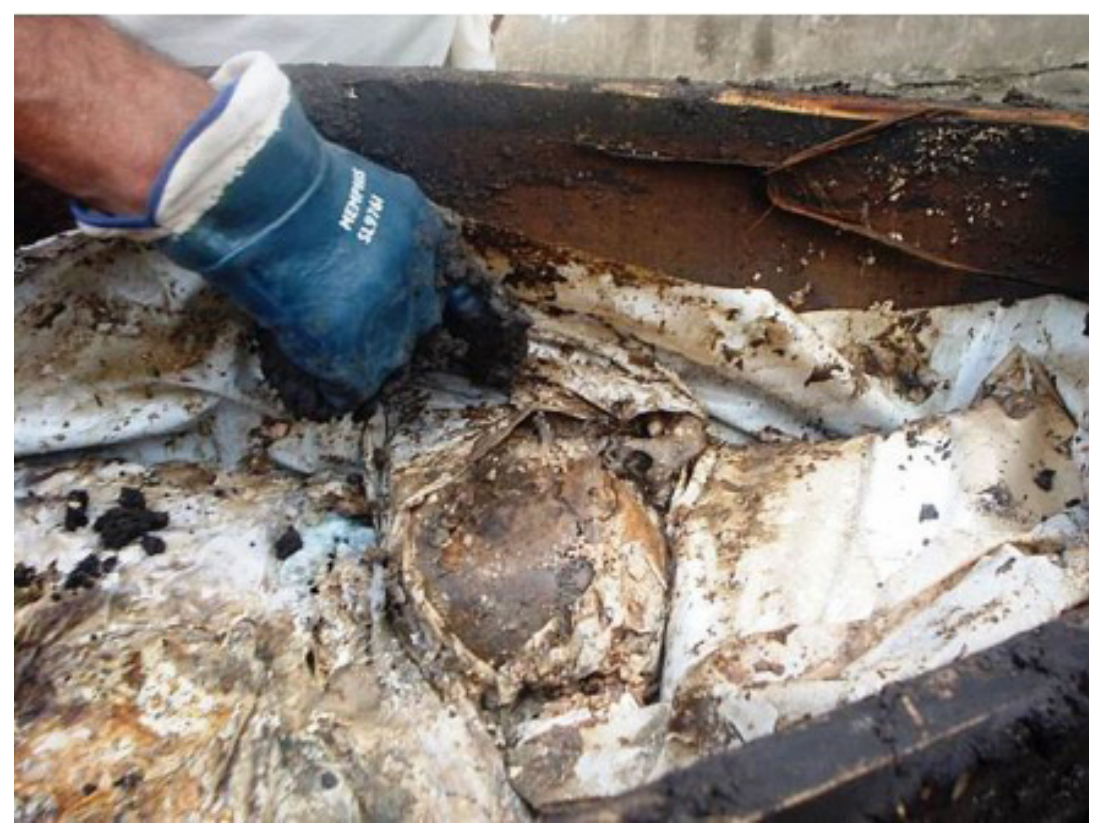

Figura 5. Cubierta de nailon sobre el cuerpo

Luego de un cuidadoso inventario, se procedió in situ a aislar y extraer piezas óseas diagnósticas las cuales fueron acondicionadas para ser descritas sucintamente a partir de observación macroscópica, con lupa de luz fría (Dolomit), y registradas fotográficamente. Las más significativas para los requerimientos judiciales incorporados a la causa se documentaron listándolas en orden numérico (Figura 6):

1. Cráneo. Estado de conservación: cranium (cráneo completo provisto de mandíbula).

2. Vértebras. Región cervical: atlas, axis, tercera cervical, ausencia de cuarta, quinta, sexta, y séptima. Región dorsal: primera a doceava vértebras dorsales. Región lumbar: primera a quinta vértebras lumbares. Sacro. Coxis.

\section{Fémures. Derecho e izquierdo.}

Observado el material, se decidió profundizar el análisis de algunos elementos esqueléticos en espacios de trabajo más adecuados mediante solicitud a la autoridad competente para su consentimiento. Producida la autorización pertinente para trasladar temporalmente dichas piezas al Laboratorio de Antropología Forense del Museo de La Plata, se embalaron adecuadamente, excepto aquellas destinadas a estudios de ADN familiar ordenado por vía separada (primera falange dedo índice mano izquierda y M1 superior derecho). 


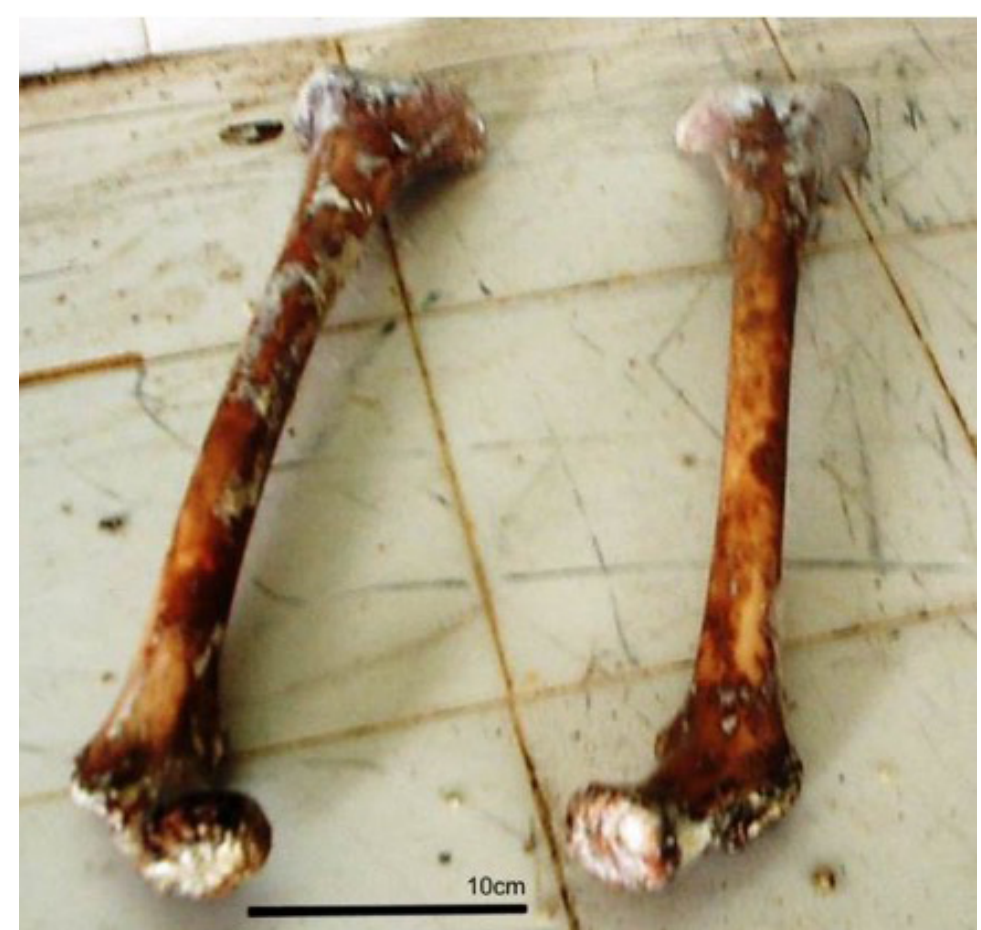

Figura 6. Fémures del individuo exhumado

\section{Resultados}

\section{Del análisis bioantropológico}

Los resultados obtenidos derivados del análisis conjunto de la actuación forense previa, de la realizada por el equipo a posteriori de la exhumación del cadáver y completada en el Laboratorio de Antropología Forense del Museo de La Plata señalaron lo siguiente:

1. Las livideces ventral y dorso-lumbar, acompañadas de manifestaciones externas incipientes de putrefacción, registradas durante la autopsia, constituyen indicadores de que la muerte se habría producido en el intervalo horario de 20 a 24 horas del día 7 de octubre de 2006, aun considerando el mantenimiento del cuerpo refrigerado.

2. El análisis bioquímico en humores y órganos de la víctima, así como de inclusiones en un durmiente del ferrocarril y otros elementos recogidos en el lugar de hallazgo, ratifican la pertenencia del individuo al Grupo 0 Factor Rh+.

3. No se registró evidencia fehaciente de que el hecho hubiera ocurrido en el lugar del hallazgo. Es más, no hubo dato relevante que sugiriera de forma documentada el espacio físico en el cual se ejecutó el crimen y las acciones derivadas (escalpado, descarne y posterior lavado). La escasísima cantidad de sangre "registrada" y "levantada" en el lugar de hallazgo corrobora lo expuesto. Es decir, todas las acciones ejecutadas que jalonan el hecho implican pasos programados secuencialmente que de ninguna manera pueden obedecer a un accionar no premeditado. Cada acción individualmente puede sugerir improvisación, pero analizadas en su conjunto responden a una planificación previa.

4. El informe histopatológico de los peritos idóneos asevera cortes vitales (en vida del individuo) en el lateral izquierdo (anterior y posterior) y cortes post mórtem en el lateral derecho. Esta comprobación permite inferir que el acto de degüello comenzó por el lateral izquierdo y que la alternativa más probable es que el individuo fuera diestro (usara su mano derecha), siendo la posición más probable estar ubicado detrás de la víctima y de pie. El corte y sección intencionales de parte de la apófisis transversa derecha de la primera vértebra dorsal, la marca de corte del cuerpo vertebral en ese lateral y de la primera costilla del mismo lado afianzan esa hipótesis, 
y este hecho representa la culminación de la operatoria para producir la separación de cabeza y cuello a nivel del final de la región cervical e inicio de la región dorsal o torácica de la columna vertebral.

5. El exhaustivo análisis realizado en el laboratorio sobre las piezas óseas exhumadas (cráneo, vértebras y fémures) determina con certeza la existencia de marcas de corte (Figura 7), algunas de ellas producto de incisiones dirigidas a separar partes anatómicas determinadas mediante la utilización de instrumentos cortantes sumamente filosos y aguzados, a saber:

- Evidencias en el cráneo de desprendimiento de partes blandas inequívocamente demostrada como obra antrópica (no cánidos) a partir del registro de marcas de corte de distribución localizada en regiones craneanas con mayor adherencia de partes blandas. El tipo, la calidad y cantidad de las líneas de corte (en torbellino) son indicativos de las características del elemento utilizado para tal fin, consistente en un pequeño cuchillo de filo liso y punta. Las zonas craneanas específicamente afectadas por la operatoria de retiro de partes blandas fueron: el frontal en ambos laterales, ambos parietales, la apófisis mastoidea izquierda y el malar izquierdo con ausencia de parte de su cuerpo y de la apófisis cigomática correspondiente.

- Evidencias en las vértebras de la separación de la cabeza y cuello del tronco, demostradas por el cercenamiento de la porción terminal de la apófisis transversal derecha de la primera vértebra torácica y cortes en la cara superior y borde anterosuperior lateral derecho del cuerpo vertebral de la misma vértebra. El instrumento cortante utilizado sin lugar a dudas fue de mediano tamaño con filo activo y aguzada punta, capaz de penetrar el hueso y dúctil para producir el desmembramiento, máxime cuando las partes anatómicas involucradas presentan superficies irregulares e inserciones musculares de importancia.

Como observación común a ambas evidencias, se destaca que quien o quienes ejecutaron el desposte demostraron en su accionar conocimiento y destreza.
6. Ante la ausencia de identificación fehaciente del individuo y la correspondencia entre partes (a través de impresiones dactilares, ADN familiar, ADN de correspondencia entre partes) al momento del hallazgo y en el trámite forense previo, el objetivo de la identificación del individuo fue abordado por el equipo desde el análisis de las piezas óseas, aportando con las estimaciones que, con distinto grado de precisión, ofrece la disciplina antropológica. De este modo, se observaron aquellos caracteres morfológicos diagnósticos en el cráneo y en el esqueleto post craneal que aproximan la estimación de edad probable. Por el grado de sinostosis de las suturas de la bóveda y la base del cráneo y el estado dentario (Figuras 7 y 8), la edad cronológica estimada es de 11 años \pm 2 por presentar erupción de ambos caninos superiores permanentes (derecho e izquierdo, piezas 1.3 y 2.3) (Ubelaker, 1978; White, 2001). Por el grado de fusión de las epífisis con sus correspondientes diáfisis en ambos fémures, observándose no unión de la cabeza femoral, de ambos trocánteres (mayor y menor) y de epífisis distal, el estadio de osificación en que se encuentra el individuo es menor a los 14 años, en tanto que la longitud máxima de ambas piezas (304 mm para el fémur derecho y 303 mm para el izquierdo) comparada con tablas estandarizadas, ubican la edad probable en el intervalo 10,5 11,5 años de edad cronológica (Ubelaker, 1978; Buikstra y Ubelaker, 1994). Por lo tanto, ambas estimaciones (de cráneo y fémures) permiten aproximar la correspondencia entre las partes (cabeza, cuerpo) como pertenecientes a un único individuo de edad probable $11 \pm 2$ años de edad cronológica. La identificación definitiva y su contrastación con el diagnóstico antropológico se realizaron a través de análisis molecular de muestras del cuerpo y del cráneo, cotejadas con muestras de familiar directo. 


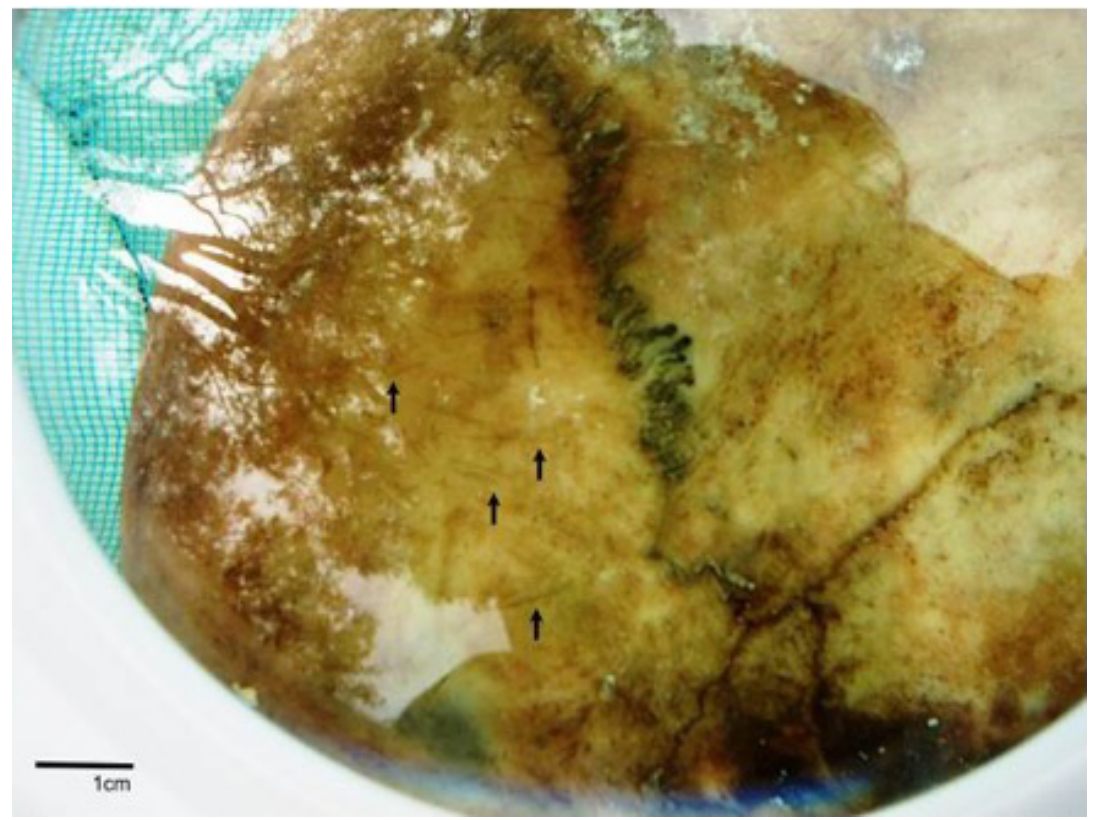

Figura 7. Cráneo y detalle de marcas de corte

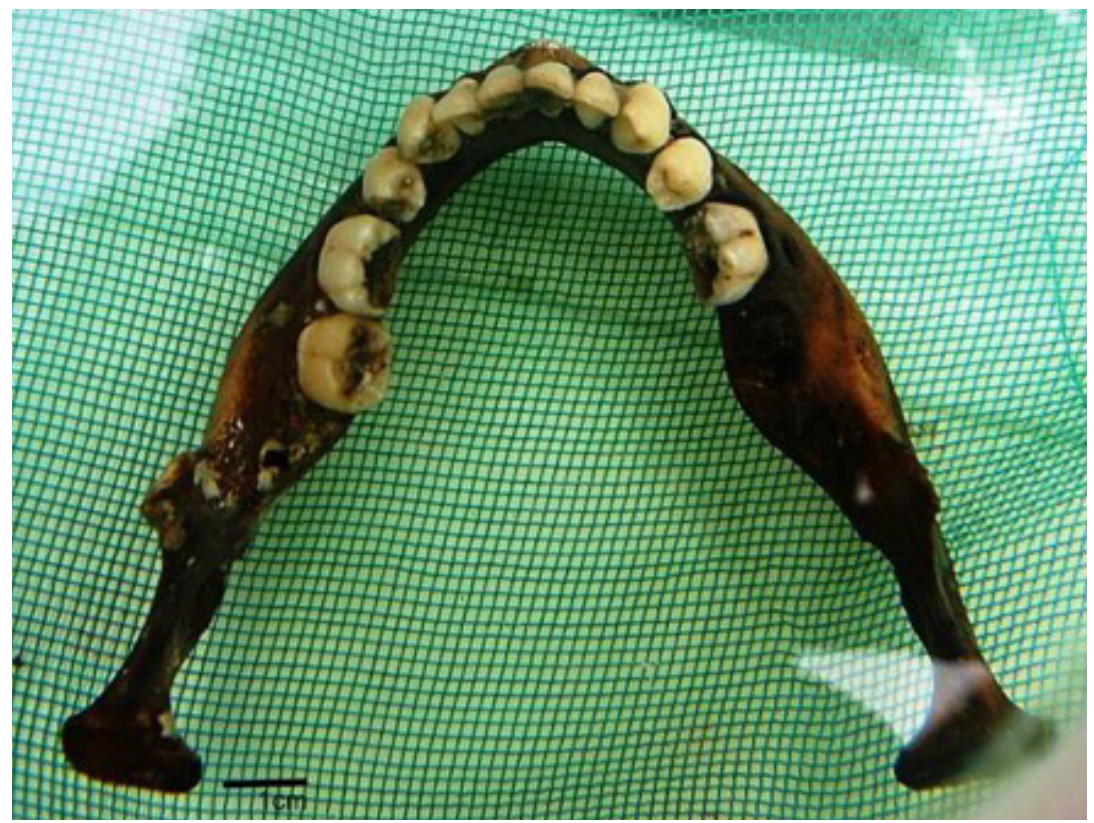

Figura 8. Mandíbula

7. Otros aportes que caracterizan el hecho y permitieron reconstruir algunas acciones del mismo tienen relación con lo siguiente:

- Las "manchas color verdoso", consecuencia de la sulfohemoglobina que producen las bacterias intestinales de putrefacción, que naturalmente aparecen en el abdomen superior, específicamente en la región del plexo solar, en este caso comienzan en las fosas ilíacas. Considerando que la localización puede modificarse por la presencia de lesiones previas a la muerte y que en el cadáver se observó una anormal dilatación del ano y fisuras perianales, la hipótesis del empalamiento por uso de un instrumento grande y rígido adquiere sustento empírico. 
- La descripción histopatológica pulmonar permitió inferir signos de asfixia y también bronco-aspiración, hechos que podrían haber sido simultáneos o bien haber ocurrido secuencialmente.

- En el análisis osteológico realizado se constata la falta de determinadas piezas óseas correspondientes a la región cervical de la columna vertebral, en particular las vértebras cuarta, quinta, sexta y séptima, ubicadas inmediatamente por encima de la línea de degüello (separación de la cabeza y cuello del tronco), plano transversal donde se ubica la primera costilla (lateral derecho) reseñada como "fracturada" en las declaraciones testimoniales de los peritos forenses.

- La depleción de lípidos corticales, observada en las secciones de glándula suprarrenal analizadas histológicamente, remite a un importante sufrimiento previo a la muerte.

\section{De la interpretación etnográfica}

El análisis semiótico previo, tanto del cadáver como del lugar de hallazgo, a través del examen minucioso de fotografías, contrastado con las evidencias provistas del estudio particularizado realizado a posteriori por el Equipo Forense-La Plata permitieron interpretar el contexto causal del crimen.

En la escena del hallazgo el cranium (cráneo completo con mandíbula) depositado sobre el hombro izquierdo, orientado a la naciente del sol, significa el anuncio de algo que está emergiendo, en este caso, la nueva organización sectaria. Cabe señalar que el lado izquierdo, conocido como la siniestra, es el lado de lo oscuro en la magia negra, la diestra (derecha) es el lado bueno y la siniestra (izquierda) se asimila al mal (Miceli, 2009).

El sufrimiento al que fue expuesta la víctima, relevado fehacientemente, tiene un significado cultural por cuanto, en la concepción cúltica, el alma sufriente se potencia y se vuelve poderosa, factor de creencia que está presente en numerosos cultos en el mundo. En este marco, la sangre también adquiere potencia vital en la concepción mágica. También la falta de elementos óseos (vértebras) implica potencialmente su uso con fines mágicos.
Sobre esta base se continuaron las investigaciones etnográficas, que incluyeron entrevistas a sospechosos, a familiares de estos, concurrencia a los allanamientos policiales, identificación y clasificación de objetos secuestrados y acceso a las declaraciones testimoniales.

Los resultados conducirían a la siguiente conclusión: El homicidio se llevó a cabo en el contexto de prácticas rituales de un culto asentado en una secta en estado primario de formación.

Se ha podido determinar que los contenidos sectarios están compuestos de una mixtura de magia negra, ritos afrobrasileños y culto al Señor La Muerte, estos dos últimos desviados de sus principios y prácticas populares. Esta secta, en formación, integraba a su práctica el uso y comercialización de drogas, prostitución infanto-juvenil y, según declaraciones testimoniales, filmaciones de pornografía y sadismo infantil. A tal fin, se reafirma que la mágico-religiosidad se retroalimenta de estos componentes, no sólo financieramente, sino en contenido comerciable y utilizable. Así, el logro de estados alterados de conciencia de manera colectiva y de estados de excitación morbosa extrema, la consecución de sensaciones y estados de poder y dominio y, principalmente, la configuración de una hermandad delictiva integrada a un nuevo orden con otros principios antisociales en este caso-, aseguran la lealtad y el secreto necesarios que derivan en la impunidad y la continuidad incrementada de la actividad. Todo ello regido por una cosmovisión mágico-religiosa, no exenta de ambiciones materiales y de poder, cuya cosmogonía se integra con otras deidades a quienes servir y adorar.

Testimonios de vecinos de los imputados confirmaron estas prácticas, así como la participación compulsiva y sojuzgamiento de niños, que por su corta edad no podían oponer resistencia, y adolescentes sobre quienes se ejercía una persuasión coercitiva. Promesas de dinero, tráfico e intercambio de objetos robados, así como prostitución infantil de niños a cuyos padres se les ofrecía dinero por entregarlos. En este contexto se adiestraba a los infantes y jóvenes en prácticas de torturas y sacrificios, a fin de reclutarlos en el 
ideario de la secta y utilizarlos con fines de lucro. Entre los objetos secuestrados se hallaron imágenes del Señor La Muerte, túnicas, máscaras, altares, cráneos y rastros de sangre en las viviendas de quienes quedaron imputados en la causa, que confirman su práctica de culto a los cráneos y cultos de sangre de manera individual y grupal. Nótese que el cuerpo de la víctima no tenía sangre y testimonios posteriores describieron su uso, el de las vértebras y las partes blandas con fines mágicos. Ambos elementos, la sangre y los huesos, son ejes integradores en el culto al Señor La Muerte que, en la creencia tradicional del nordeste argentino, se alimenta simbólicamente de sangre y su iconografía es un esqueleto con una guadaña. Los cultos afrobrasileños utilizan sangre animal y el satanismo también utiliza frecuentemente cráneos y sangre en prácticas rituales, porque es el líquido vital que potencia las prácticas mágicas, especialmente cuando se trata de niños y púberes que han sido bautizados. La aparición de un gato negro ahorcado en el lado izquierdo de la tumba del niño asesinado implica en las prácticas satánicas la guía del alma hacia la oscuridad. Esto tiene su correlato también en el hecho de que a la víctima le sacaron los ojos.

\section{Consideraciones finales}

Las hipótesis sostenidas durante los cinco años que duró la investigación, hasta llegar a la etapa de juicio oral, fueron aceptadas en pocas oportunidades. En la mayor parte de la etapa investigativa fueron resistidas y combatidas y, además, contaminadas con intereses de sectores políticos y de poder que se veían involucrados, lo que generaba incredulidad y rechazo general en ciertos sectores de la sociedad. Afortunadamente, el manejo firme, adecuado y paciente de las autoridades judiciales hizo que esas hipótesis se vieran finalmente corroboradas en su totalidad por confesiones, testimonios y hallazgos, entre ellos un manual de magia negra, que detallaba un sacrificio de ofrenda cuyos pasos coincidían exactamente con todas las acciones que fueron llevadas a cabo con la víctima.

El juicio oral concluyó en 2011 con nueve condenas y, aunque fue tipificado de acuerdo al Código Penal Argentino, se constituyó en el primer caso de condenas por crimen sectario confirmadas por la Suprema Corte de Justicia de la Nación Argentina. En 2015, otro miembro de la secta y autor del homicidio fue detenido y condenado a perpetua. De los condenados en 2011, una mujer se mantuvo prófuga durante trece años y recientemente fue apresada y puesta a disposición de la justicia para cumplir su condena.

Consideramos que la antropología posee una perspectiva comparativa e integradora que permite abordar la conducta criminal como conducta culturalmente constituida y bio-culturalmente externalizada, como la que por excelencia interviene en la salud y la muerte humanas. Es este el rumbo que entendemos debe tomar la antropología forense para volver a sus fuentes epistémicas y robustecer su desarrollo.

\section{Referencias bibliográficas}

Buikstra, J. and Ubelaker, D. (Eds.) (1994). Standards for data collection from human skeletal remains. Proceedings of a Seminar at the Field Museum of Natural History. Fayetteville: Arkansas Archaeological Survey Research Series № 44. USA.

Cattaneo, G. R. (2007). Forensic anthropology: developments of a classical discipline in the new millennium. Forensic Science International, 165(23), 185-193.
Chaves de Azcona, L. E. (1971). Informe pericial caso Felipe Vallese. Tribunales de la Provincia de Buenos Aires. La Plata, Argentina.

Dasso, M. C., Palmer, J., Braunstein, J. y Pignocchi, J. L. (2006). Juicio y prejuicio en la justicia penal provinciana. Incumbencias de una etnografía postcolonial genuina. XXVIEncuentro de Geohistoria Regional (IIGHI - Conicet). Resistencia, Argentina.

Desántolo, B., Lamenza, G., Balbarrey, G., Ramallo, V., De Feo C., Calandra, H., Braunstein, J., Salceda, S. (2013). Territorialidad y laudo forense. El caso 
Misión Esteros (Formosa, Argentina). Folia Histórica del Nordeste, (21), 155-167.

Desántolo, B. (2013). Validación metodológica para la estimación de edad en restos óseos humanos adultos: análisis histomorfométrico (Tesis doctoral). Universidad Nacional de La Plata, Argentina.

Fondebrider, L. (2007). Arqueología forense: estado actual de desarrollo. IV Reunión Internacional de Teoría Arqueológica en América del Sur. San Fernando del Valle de Catamarca, Argentina.

García Mancuso, R. (2013). Análisis bioantropológico de restos esqueletales de individuos subadultos. Diagnóstico de edad y sexo, validación técnico metodológica (Tesis doctoral). Universidad Nacional de La Plata, Argentina.

Gassiot Ballbe, E. y Palomar Puebla, B. (2000). Arqueología de la praxis: información histórica de la acción social. El caso de la Unión de Cooperativas agropecuarias de Miraflor, Nicaragua. Complutum, 11(87).

Krogman, W. M. and İşcan M. Y. (1986). The Human Skeleton in Forensic Medicine. Springfield, IL, USA: Charles C Thomas.

Martínez Marignac, V. (2000). Derechos de las minorías aborígenes: aportes de la genética molecular a la identificación amerindia (Tesis doctoral). Universidad Nacional de La Plata, Argentina.

Miceli, J. (1998). Informe Final. Estudio de plantas indígenas de uso medicinal y mágico en Corrientes, Argentina. Tide Center/TheEthnobiology and Conservation Team. Washington D.C., USA. Documento sin publicar.

Miceli, J. (2009). Informe Final Expediente 14.836/06 "De Oficio por homicidio-Mercedes" para Juzgado de Instrucción y Correccional de Mercedes. Corrientes, Argentina. Documento sin publicar.

Miceli, J. y Ríos, S. (2009). De la antropología general a la antropología forense. $V$ Congreso de Antropología Forense. Asociación Latinoamericana de Antropología Forense. Buenos Aires, Argentina.

Plischuk, M. (2012). Detección y diagnóstico de patologías en restos óseos humanos: aproximación epidemiológica a una muestra documentada (Tesis doctoral). Universidad Nacional de La Plata, Argentina.

Politis, G. (2002). South America: In de Garden of Forking Paths. In B. Cunliffe, W. Davies y C. Renfrew (Eds.), Archaeology. The Widening Debate. Oxford: British Academy of Oxford University Press.

Salceda, S., Calandra, H. y Restelli, M. (2007). Informe pericial en la causa caratulada "De Oficio p/homicidio-Mercedes-Expte. № 14.836/06" Mercedes, Corrientes, Argentina.

Salceda, S., Calandra, H., De Feo, C., Desántolo, B., Balbarrey, G., Lamenza, G., ..., Zapiola, L. (2009). Arqueología pública y pueblos originarios. V Congreso de Antropología Forense. Asociación Latinoamericana de Antropología Forense. Buenos Aires, Argentina.

Salceda, S., Calandra, H. y Villanueva, G. (2010). Las paradojas de lo legal: aportes de la antropología. Intercambios. Revista de la Especialización en Derecho Penal, (14), 1-4.

Salceda, S., Desántolo, B. y Plischuk, M. (2015). Espacio de reflexión; el por qué y el para quién de la investigación bioantropológica. Revista Argentina de Antropología Biológica, 17(2), 1-6. Recuperado de https://revistas.unlp.edu.ar/raab/article/view/1514

Stewart T. Dale (1979). Essentials of Forensic Anthropology: Especially as Developed in the United States. Springfield, IL, USA: Charles C. Thomas.

Ubelaker, D. (1978). Human skeletal remains. Excavation, analysis, interpretation. Chicago: Aldine Publishing Company.

White, T. (2001). Human osteology. California, USA: Academic Press.

Zarankin, A. y Fondebrider, L. (2007). Historias desaparecidas: Arqueología de la represión. IV Reunión Internacional de Teoría Arqueológica en América del Sur. San Fernando del Valle de Catamarca, Argentina. 